\title{
TITLE: APPLICATION OF RESERVOIR CHARACTERIZATION AND ADVANCED TECHNOLOGY TO IMPROVE RECOVERY AND ECONOMICS IN A LOWER QUALITY SHALLOW SHELF CARBONATE RESERVOIR
}

Cooperative Agreement No.: DE - FC22 - 94BC14990

Contractor Name and Address: Oxy USA, Inc. (Oxy), Midland, Texas

Date of Report: November 1, 1995

Award Date: August 3, 1994

Anticipated Completion Date: June 14, 1996 - Budget Period 1

Government Award for Current Fiscal Year: $\$ 2,023,000$

Principal Investigators: Archie R. Taylor (Oxy)

Project Manager: Chandra Nautiyal, Bartlesville Project Office

Reporting Period: July 1, 1995 - September 30, 1995

\section{OBJECTIVES}

The Class 2 Project at West Welch was designed to demonstrate the use of advanced technologies to enhance the economics of improved oil recovery (IOR) projects in lower quality Shallow Shelf Carbonate (SSC) reservoirs, resulting in recovery of additional oil that would otherwise be abandoned. Accurate reservoir description is critical to the effective evaluation and efficient design of IOR projects in the heterogeneous SSC reservoirs. Therefore, the majority of Budget Periodd w was devoted to reservoir characterization. Technologies being demonstrated include:

1.Advanced petrophysics

2.Three dimensional (3-D) seismic

3.Cross-well bore tomography

4.Advanced reservoir simulation

5. Carbon dioxide $\left(\mathrm{CO}_{2)}\right.$ stimulation treatments

6.Hydraulic fracturing design and monitoring

7.Mobility control agents

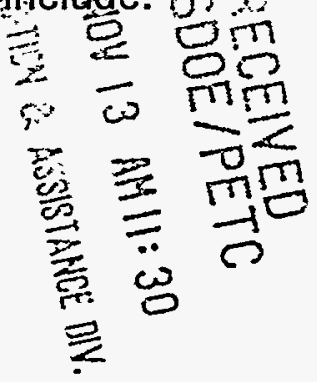




\section{SUMMARY OF TECHNICAL PROGRESS}

West Welch Unit is one of four large waterflood units in the Welch Field located in the Northwestern portion of Dawson County, Texas. The Welch Field was discovered in the early 1940's and produces oil under a solution gas drive mechanism from the San Andres formation at approximately $4800 \mathrm{ft}$. The field has been under waterflood for 30 years and a significant portion has been infilled drilled on 20-ac density. A 1982-86 pilot $\mathrm{CO}_{2}$ injection project in the offsetting South Welch Unit yielded positive results. The recent installation of a $\mathrm{CO}_{2}$ pipeline near the field allowed the phased development of a miscible $\mathrm{CO}_{2}$ injection project at the South Welch Unit.

The reservoir quality is poorer at the West Welch Unit because of its relative location of sea level during deposition. Because of the proximity of a $\mathrm{CO}_{2}$ source and the $\mathrm{CO}_{2}$ operating experience that would be available from the South Welch Unit, West Welch Unit is an ideal location for demonstrating methods for enhancing economics of IOR projects in lower quality SSC reservoirs. This Class 2 project concentrates on the efficient design of a miscible $\mathrm{CO}_{2}$ project based on detailed reservoir characterization from advanced petrophysics, 3-D seismic interpretations and cross wellbore tomography interpretations.

During the quarter, substantial progress was made in both the petrophysical analyses and the tomography processing. Both of these phases are running behind schedule. The geologic model is dependent upon the petrophysical analysis and the seismic and tomography interpretations. The actual reservoir simulation cannot start until the geologic model is complete, although all the preliminary simulation work is being done.

\section{PETROPHYSICAL ANALYSIS}

Sequence stratigraphy indicates periodic flooding of the study area during deposition that created thin beds of fine grain, non-permeable material. These beds create no-flow boundaries that extend across the demonstration area and can be identified from the gamma-ray logs. Use of the gamma-ray logs to identify no-flow boundaries have increased the number of layers in the geological model from 8 to 11 . This increases the likelihood that there are un-perforated flow units in some of the wells. Further division of the zones between the flow barriers into the four established rock types will be attempted which may add additional layers to the geologic model.

Further work with the Carmen Kozeny equation resulted in derivation of a permeability relationship utilizing information from standard porosity-resistivity log suites. The use of neural network analysis helped identify what log responses have meaningful relationships to the functions in the Kozeny equation. Gamma-ray log response has been found to correlate to surface area. Resistivity response has been 
used to derive the required cementation factor. The resulting equation is shown below:

$$
K=\frac{100 \times \phi^{3}}{m_{N R} \times G R^{2} \times(1-\phi)^{2}}
$$

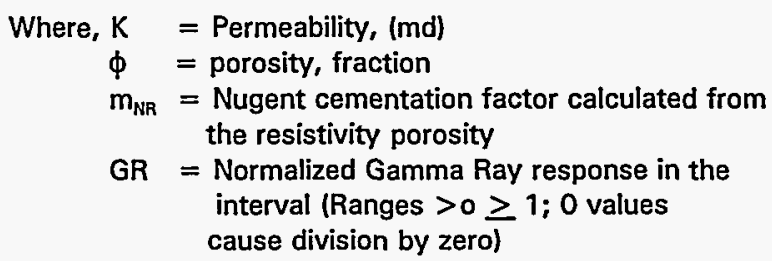

A comparison of the calculated permeability from log data (solid line) to whole core permeability (dashed line) is shown by Figure 1.

\section{3-D SEISMIC INTERPRETATION}

New seismic guided $\phi \mathrm{H}$ maps will incorporate the revised layering obtained from the petrophysical work. Also, tomography data will be merged with the surface seismic data to attempt to refine the vertical resolution.

\section{TOMOGRAPHY}

Processing is nearing completion on all portions of the tomography data. Compressional wave, interwell-VSP, shear-wave, and reflection tomograms are complete. The first Poission's ratio tomogram is complete with the remainder waiting on computer resources.

\section{RESERVOIR SIMULATION}

Work has concentrated on gathering completion information and laboratory data, to use in the waterflood history match; since the geologic model is not ready. Layer thicknesses are ready for use in the model. The next steps will include setting well completion intervals and building production rate files from historical data.

\section{$\mathrm{CO}_{2}$ STIMULATION TREATMENTS}

The latest data from the five $\mathrm{CO}_{2}$-treated wells, shows one well with less than a one year payout, and the other four not reaching pay out, even with a $\$ .70 / \mathrm{MCF}$ $\mathrm{CO}_{2}$ price. Additional study, which incorporates the reservoir characterization work, is needed to explain why the other four wells failed to payout. Issues to investigate include:

1. How does treatment size effect results when the net pay is then compared to the gross interval? 
2. Should treatment intervals be limited to certain layers?

3. What affect do low pressure discontinuous layers have on production response?

\section{HYDRAULIC FRACTURING}

Initial passive seismic results from the fracture treatment on the 4807 well were not as anticipated. The initial interpretation identified 30 seismic events that have at least 5 clear signals from different stations. An additional 229 events with 4 clear signals may add to the current interpretation. Results from the 30 events, shows one wing of the fracture extends over 500 feet to the east with one event occurring at 90 degrees to and 500 feet from the east end of the fracture. Similar results have been reported by other investigators'. Propagation of the other wing appears to have gone to the southeast for over 1000 feet. However, the seismic events, at the ends of the fracture, suggest that the fracture grew upward, completely out of the main pay.

The falloff analysis gave more conventional results, showing an effective fracture half length of 400 feet assuming 60 feet pay thickness. This is similar to the fracture area predicted by the fracture modeling. However, the post-fracture model shows the fracture grew out of zone at the wellbore, with a fracture height of 174 feet and a half length of 180 feet. Another fracture treatment is planned on a new untreated well, to gain additional insight into fracturing mechanics.

\section{TECHNOLOGY TRANSFER}

During the quarter, presentations were made by team members to a total of 242 people with three industry groups within the Permian Basin. On September 12, 1995, $\mathrm{Mr}$. George Watts spoke to the monthly meeting of the West Texas Geological Society on methods of converting seismic attributes to log properties. The presentation included the pore volume maps generated at the West Welch project.

An all day seminar was held September 22, 1995 at the CEED/Petroleum Industrial Alliance Facility between Midland and Odessa, Texas that presented the results to date of the West Welch project. Five different team members made presentations concerning the engineering, petrophysic, geologic, seismic and tomographic aspects of the project. Included was an actual demonstration of the seismic attribute to log property conversion method using commercially available low cost software on a PC. The seminar was fully subscribed with 105 registered and another seminar is planned in November 1995 to accommodate the overflow.

The reservoir characterization research lab held its Fall Industrial Associates meeting in Carlsbad on October 20-21, 1995 under the sponsorship of the Bureau of Economic Geology. Oxy team members prepared two posters for this meeting. One illustrated the use of seismic attributes to estimate log properties. The other included examples of the tomograms that have been developed at West Welch. 


\section{REFERENCES}

1. N. R. Warpinski, B. P. Engler, C. J. Young, R. Peterson, P. T. Branagan and J. E. Fix, Microseismic Mapping of Hydraulic Fractures Using Multi-Level Wireline Receivers, paper SPE 30507 presented at the 70th SPE Annual Technical Conference, Houston, TX, October 22 - 25. 1995. 


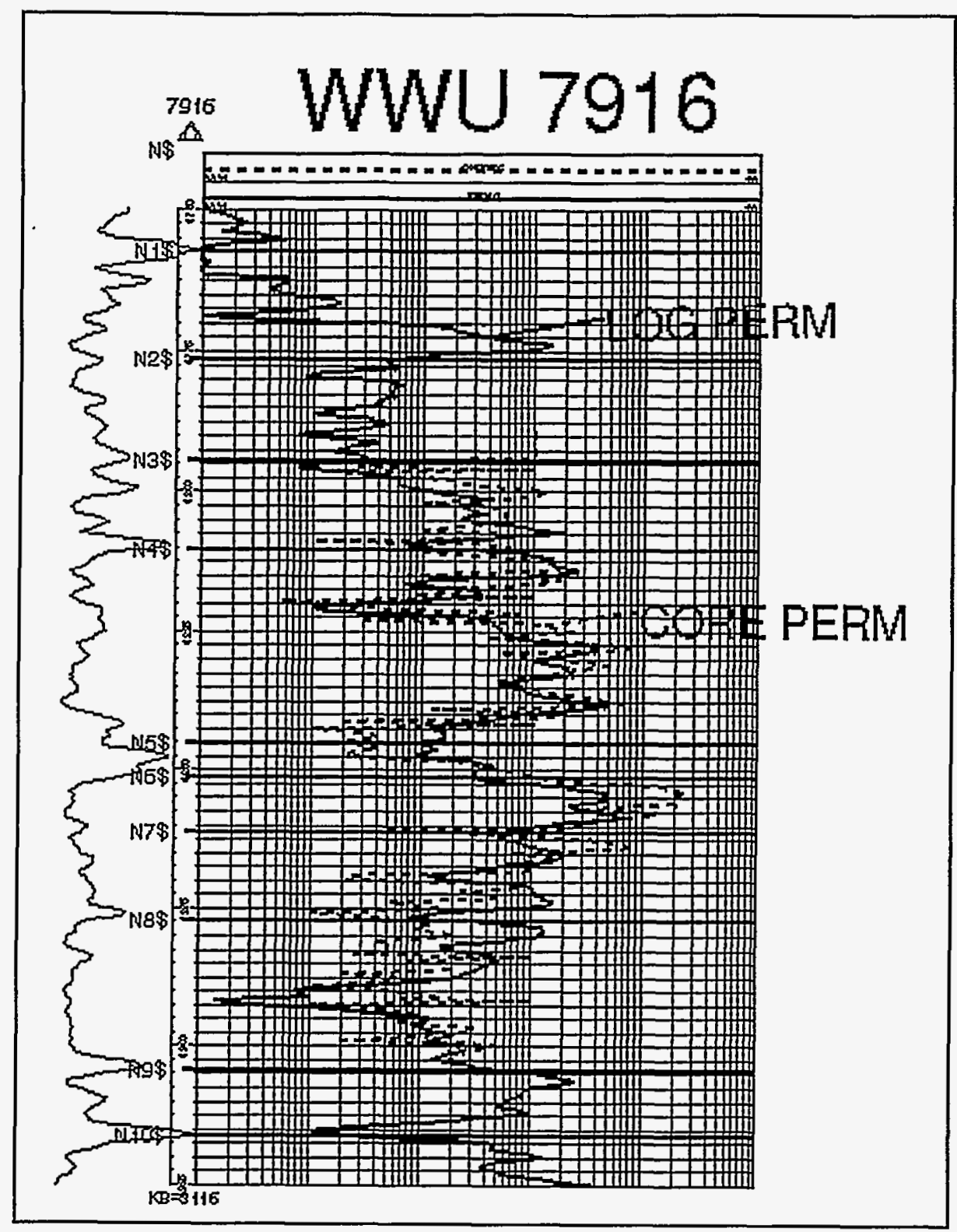

\section{DISCLAIMER}

This report was prepared as an account of work sponsored by an agency of the United States Government. Neither the United States Government nor any agency thereof, nor any of their employees, makes any warranty, express or implied, or assumes any legal liability or responsibility for the accuracy, completeness, or usefulness of any information, apparatus, product, or process disclosed, or represents that its use would not infringe privately owned rights. Reference herein to any specific commercial product, process, or service by trade name, trademark, manufacturer, or otherwise does not necessarily constitute or imply its endorsement, recommendation, or favoring by the United States Government or any agency thereof. The views and opinions of authors expressed herein do not necessarily state or reflect those of the United States Government or any agency thereof.

Figure 1 
